\title{
Article \\ Optimizing Multimodal Transportation Routes Considering Container Use
}

\author{
Dandan Chen ${ }^{1, *}$, Yong Zhang ${ }^{1}$, Liangpeng Gao ${ }^{2}$ and Russell G. Thompson ${ }^{3}$ \\ 1 School of Transportation, Southeast University, Nanjing 210096, China; zhangyong@seu.edu.cn \\ 2 School of Transportation, Fujian University of Technology, Fuzhou 350118, China; \\ LiangpengGao.Acad@gmail.com \\ 3 Department of Infrastructure Engineering, University of Melbourne, Victoria 3010, Australia; \\ rgthom@unimelb.edu.au \\ * Correspondence: seuchendandan@163.com
}

Received: 13 August 2019; Accepted: 24 September 2019; Published: 26 September 2019

\begin{abstract}
This study focuses on the route selection problem of multimodal transportation: When facing a shortage of containers, a transport plan must be designed for freight forwarders that realizes the optimal balance between transportation time and transportation cost. This problem is complicated by two important characteristics: (1) The use of containers is related to transport routes, and they interact with each other; and (2) Different types of containers should be used in different time ranges for different modes of transportation. To solve this problem, we establish a multi-objective optimization model for minimizing the total transportation time, transportation cost and container usage cost. To solve the multi-objective programming model, the normalized normal constraint method (NNCM) is used to obtain Pareto solutions. We conducted a case study considering the transportation of iron ore in Panzhihua City, Sichuan Province. The results demonstrate that using railway containers and railway transportation as much as possible in route selection can effectively solve the problem of container shortage and balance transportation time and transportation cost.
\end{abstract}

Keywords: routing optimization; multimodal transportation; multi-objective; containers

\section{Introduction}

With the increasing global economic integration, the sustainable development of world economy and society needs the support of an efficient freight transportation system [1] (Wu and Chang, 2019). By relying on two or more modes of transportation, multimodal transport can substantially improve transport efficiency and reduce transportation costs for the entire process integration organization transportation service. According to statistics, multimodal transport can improve transportation efficiency by $30 \%$, reduce cargo damage by $10 \%$, reduce transportation costs by $20 \%$, reduce highway congestion by more than $50 \%$, and promote energy savings and emissions reduction by more than one third [2]. Multimodal transport has been vigorously promoted and developed all over the world. According to statistics, multimodal transport accounts for $80 \%$ of the total traffic in Canada and it is estimated that by 2040 , the total freight volume of the United States will reach 3.575 billion tons, accounting for $12.5 \%$ of the total freight volume. Under its influence, China has also begun to vigorously develop multimodal transport. According to China's logistics industry development plan, the volume of multimodal freight in China is expected to reach 3.02 billion tons by 2020 and will account for approximately $6 \%$ of the total freight volume of the whole country, which demonstrates the broad development prospects of multimodal transport in China [3]. As a new mode of transport organization, container-based multimodal transportation can improve transport efficiency, achieve "door-to-door" 
transport, reduce the damage and loss of goods caused by intermediate links and replacement, and has become the main development form of multimodal transport $[4,5]$

The vast logistics market and strong freight demand has led to the creation of many multimodal freight forwarding enterprises. These enterprises identify the transport needs of shippers, formulate multimodal transport plans and implement transport operations and they are the actual organizers and promoters of the development of multimodal transport [6]. However, various challenges are inevitably encountered in transportation operations. For example, due to the restriction on regional industrial development, unbalanced cargo flow often leads to unbalanced container flow. In many areas, empty containers are overstocked, whereas in other areas, container shortages occur occasionally. If there is a shortage of containers, freight forwarders will be unable to implement transport plans in time to satisfy the carrier's transport time requirements and will face the risk of default and the decline in their service reputation $[7,8]$. As the largest material base of iron ore and titanium in China, Panzhihua is one of the four major iron ore deposits in China and it is also known as "the world's capital of vanadium and titanium". There are nearly 10 billion tons of proven reserves of vanadium-titanium magnetite in this city. Among these reserves, the vanadium reserves account for $87 \%$ of those in China, ranking third in the world, and titanium reserves account for $94.3 \%$ of the proven reserves in China, which ranks first in the world [9]. The long-term stable transportation demand for vanadium and iron ore export has led to the growth of many multimodal freight forwarding enterprises. However, the volume of freight imports in this area is much lower than the volume of freight exports. Hence, the multimodal freight forwarding enterprises often face a shortage of containers.

Typically, there are three ways to solve the problem of container shortages for freight forwarding enterprises. The first is to own the containers. These self-owned containers have no use restrictions on the time or on the mode of transport. This option is the most flexible. However, the cost of purchasing containers is very high and containers will be lost during use and have a high risk of vacancy [10]. The second approach is to charter the shipping company's containers. Leasing containers can reduce the purchase cost and the vacancy risk of freight forwarders, thereby reducing the maintenance and management costs of containers simultaneously [11]. In terms of quantity, the container stock of shipping companies is much larger than that of freight forwarding enterprises. That is to say, if there is no restriction on using conditions, enterprises can rent unlimited container of shipping companies. In the process of container leasing, freight companies must pay rent to the shipping company. The longer they use the containers, the more rent they pay. To maximize their profits, shipping companies typically lease containers to freight forwarders who use shipping companies' fleets for waterway transport. Hence, if freight forwarders want to lease containers of shipping companies, they must consider waterway transport when formulating their multimodal transport schemes. Sometimes, water is clearly not a wise choice for goods that require short-term, fast delivery which means no shipping company containers can be used. Finally, freight forwarders can use railway containers [12].

Railway stations are a state-controlled department that has a strong financial and business guarantee. Compared with freight enterprises, railway stations have a certain container stock. In a sense, there will be no shortage of railway containers for freight companies to lease. However, railway containers are managed and dispatched by the State Railway Administration, which imposes many restrictions on the use of their containers. First, if freight forwarders want to borrow railway containers, they must use the railway transport mode. Secondly, various limitations are imposed on the use times of railway containers according to the transport conditions. If only railway transport in combination with road transport is used, the time limit for using each railway container is approximately 7 days. After 7 days, the container must be returned to the railway freight station. If water transport is carried out during railway container transportation, the railway administration will extend the use time accordingly. However, the use time cannot exceed 12 days. As the main waterway from the southwest to the southeast of China, the Yangtze River is congested, and the transport time is uncontrollable. Therefore, if railway containers are transported by water, freight transport enterprises 
will face the risk of overdue return times for containers. If the containers are returned when they are overdue, the enterprise will incur a poor use record in the railway freight transport system, which will result in late fines and will render it more difficult to rent containers next time.

When making transport plans, freight forwarding enterprises must carefully calculate the cost of using containers and weigh the conditions of using containers. Conversely, it is also a constraint of "container shortage". After all, there are potential economic risks for individuals to hold redundant containers. The main contribution of this paper is to establish a multi-objective programming model to solve the multimodal transportation planning problem when freight forwarders are facing container shortage, considering the binding of container usage and transport modes.

The three main objectives of this paper are:

(1) Minimizing the total transportation cost to maximize the profit of freight forwarders;

(2) Minimizing the total transport time to meet the shipper's transport time requirements;

(3) Minimizing the use cost of containers, when freight forwarders are facing container shortage, and reducing the cost of enterprises as much as possible.

The remainder of the paper is organized as follows: the third part introduces the optimization model of the routing problem for multimodal transport under a container usage restriction; the fourth part describes the solution algorithm for the model; the fifth part presents the case study; and the last section presents the conclusions of this work and discusses its prospects.

\section{Literature Review}

As a key research area in tactical planning problems of multimodal freight transportation, route optimization is used to select the transport service mode and the arc in the transportation network, which has attracted wide attention from scholars [2]. As a precursor, Barnhart [13] explored the truck-rail multimodal routing problem. They regard the routing optimization problem as a shortest path problem in which the objective is to minimize the transportation cost and the inventory cost and use a b-matching algorithm to solve it. Subsequently, many scholars have investigated the routing optimization of multimodal transportation. These studies are grouped into three main categories.

The first category corresponds to the conventional optimization problems. Among them, the route planning problem with a time window is one of the most popular research areas. According to the present research, a type of time window is defined for the nodes in the transportation network. Each node stores the earliest and latest acceptable arrival times of products and the limited scheduled departure time. The main objective of these problems is to identify optimal paths that minimize the total transportation cost and the travel time while satisfying the time window constraints $[14,15]$. Another type of time window is defined for transportation services that have a limited start time of loading and cut off $[16,17]$. Trucks, maritime services and trains are used to minimize the total transportation costs and most of these studies are aimed at multimodal transport of multi-products. In addition to the time window, other constraints have been studied by scholars: In the process of multimodal transport, transshipment is unavoidable. In the research of Sun and Lang [18], the transshipments are considered at each node in the transportation network. Transshipments between transportation modes will incur replacement costs and time costs, which are considered in the objective function. The capacity limits of cargo volume at each seaport and vehicle at each transportation mode are considered in Kim's study [19]. Moreover, the carbon emission cost is considered in the objective function of the model [20]. The objective functions of these papers can be divided into two types: single-objective, in which minimizing transport costs is the main objective, and multi-objective, in which minimizing the transportation time and cost is the most common objective. The inventory cost, the carbon emission cost, the loading and unloading cost and the transshipment cost will also be considered.

Due to the many participants and transport links, there are substantial uncertainties in the process of multimodal transport [21-23]. The multimodal transportation path planning problem in an uncertain environment has attracted much attention from scholars. The ever-changing market can influence 
customers' demand at any time. Only when the actual transportation begins can the demand be truly determined. Therefore, scholars have studied the uncertainty of the demand. Triangular fuzzy numbers are often used to describe the demand uncertainty in the routing problem of road-rail multimodal transportation [24-26]. To improve flexibility, Sun [27] used trapezoidal fuzzy numbers to describe the uncertain demand. In contrast to fuzzy programming, Cao [28] used stochastic programs to express the random demands in a transportation network with a single origin and multiple destinations. Stochastic programming is used to describe the uncertainty of the demand in Dong's research [29] to solve the problem of shipment routing with service capacity planning. In that study, a container routing model is constructed as a dynamic link-based routing model and the sample average approximation algorithm is used to solve it. In addition, the uncertain demand for containers is considered in the problem of short-term liner ship fleet planning to identify an optimal ship route to maximize the total cost [30].

In terms of the time uncertainty, the randomness of transport time can be expressed by setting the probability of delivery within a specified time range and the probability of completing the transport mission within the specified time range [31]. The travel time uncertainty of road services that is caused by traffic congestion was studied by Rouky and Sun [32,33], and the influence of $\mathrm{CO}_{2}$ emissions on the dynamic routes are also considered. However, in transport networks, multi-product flows often have multiple origin-destinations (ODs). The capacity uncertainty of rail services and the travel time uncertainty of road services have been studied $[20,34]$ with the objective of optimizing the $\mathrm{CO}_{2}$ emissions in the routing. Yang et al. [35] considered uncertainty in the unit transportation cost, which is regarded as a fuzzy variable in the rail traffic system, and uncertainty in the transportation capacity of arcs in a complex system with multiple ODs and set the upper limit of the transport distance for each route.

Finally, the problem of routing optimization is considered in a multimodal transport network as a location-routing problem (LRP). Selecting the facility locations and the routing of vehicles simultaneously will yield superior, non-suboptimal solutions [36]. Decision making typically involves the selection of open construction facilities, which include distribution depots and mode changing facilities, and the matching between vehicles and demand customers. An LRP with a time window requires products to be delivered to the customer within a limited transportation time. An LRP in an uncertain environment considers uncertainty in, e.g., the demand or the time, which has attracted the attention of many scholars. Random variables and fuzzy variables are the two most common ways of describing uncertainty. The objective function of this problem typically minimizes the costs of facility construction and transportation [24,37-40].

In addition, several papers have focused on the container routing and scheduling of liner shipping companies $[30,41]$ and the current research on containers mainly focuses on empty container repositioning. These studies involve the rational allocation and scheduling of empty containers without cargo loading in the process of cargo transportation. The main purpose of these studies is to balance the number of containers in various places and avoid the backlog of empty containers in one place and the shortage of empty containers in another place [42-50].

Overall, route planning, which is a key tactical planning problem, has been extensively studied in both routine scenarios and uncertain environments. The main objective of these papers is to reduce transport costs, transport time and carbon emissions by optimizing transport routes from the perspective of the carrier. As the main carrying tool of multimodal transport, freight forwarding enterprises sometimes face shortages of containers. However, most studies assume an adequate number of containers. This paper mainly focuses on the scenario in which freight forwarders must consider the links between containers and transport routes when planning multimodal transport routes in the case of a shortage of containers.

\section{Problem Description and Mathematical Formulation}

This paper presents a routing design for a freight forwarder who is the organizer and implementer of multimodal transport from a specified origin point to a specified destination. The freight company 
must establish the transport channels—-that is, it must construct a multimodal transportation network. Transport nodes, such as railway stations, ports, and routes, constitute the most important part of the network. Once the network has been constructed, the freight company will choose the nodes and routes for the transportation scheme. However, containers are indispensable in the transportation process as an important means of transport. In parts of China, the freight company must consider the container availability prior to formulating the transportation plan due to the shortage of containers. If there are no available containers, transportation will become impossible. Typically, the three most common approaches to container acquisition for a freight company are the use of railway containers, the use of the ship company's containers and the use of self-owned containers. Each approach has shortcomings: A railway container and a ship company's container must be utilized via rail transport and water transport, respectively, whereas a self-owned container will generate high acquisition and management costs. Therefore, we establish a multi-objective model for minimizing the transportation time and the costs that are incurred during transportation, which include the transshipment cost and the usage charges of containers. This model aims at selecting an optimal route for transporting goods from its origin to its destination via multimodal transport networks while satisfying the time requirement of the shipper and considering the availability of containers. With reference to $[15,18]$, the main assumptions of the model are as follows:

- Goods should be transported at one time and cannot be transported in batches.

- Only one type of container is used throughout the transportation process.

- Transportation between two conjoint nodes should use only one arc and one transportation mode.

- Transportation between two conjoint nodes should use only one container.

- If transshipment is required at a node, the number of consignment transshipments at the node should not exceed one.

- The number of times that the consignment of goods is transported across a node should not exceed one.

- The total transportation time of the consignment of goods should not exceed the transit period of the goods.

- The total transportation time of the consignment of goods should not exceed the time limit of the containers.

Let $G=(N, A, M, R)$ denote the multimodal transportation network, where $N$ is the transportation node set, $A$ is the transportation arc set, $M$ is the transportation model set and $R$ is the container set. Let $o, d$ and $T_{r}$ denote the origin node, the destination node and the candidate transhipping node. Then, $N=T_{r} \cup(o, d)$. The parameters and the decision variables in the model are defined as follows:

Sets:

N: Transportation node set.

A: Transportation arc set.

$M$ : Transportation model set.

$R$ : Container set.

I: Conjoint node set of node $i$, with $I \in N$.

\section{Parameters:}

Q: Number of containers (measured by TEU) that are carrying the consignment of goods.

$h, i, j$ : Indices of the transportation nodes in the multimodal transportation network.

$k, l$ : Indices of the transportation modes in the multimodal transportation network.

$C_{i, j}^{m}$ : Transportation cost of transportation mode $m$ on arc $(i, j)$.

$d_{i, j}^{m}$ : Transportation distance of transportation mode $m$ on arc $(i, j)$.

$v_{i, j}^{m}$ : Transportation speed of transportation mode $m$ on $\operatorname{arc}(i, j)$.

v: Transhipping cost at node $i$ from mode $k$ to mode $l$.

$T_{i}^{k l}$ : Transhipping time at node $i$ from mode $k$ to mode $l$. 
$T_{r}^{m}$ : Limited use time of container $r$ under mode $m$.

$C_{r}$ : Use cost of container $r$.

$T$ : Transit period of goods.

\section{Decision variables:}

$X_{i, j}^{m}: 0-1$ decision variable. If the consignment of goods is transported across arc $(i, j)$ via transportation mode $m, X_{i j}^{m}=1$; otherwise, $X_{i j}^{m}=0$.

$Y_{i}^{k l}: 0-1$ decision variable. If the consignment of goods is transhipped from transportation mode $k$ to mode $l$ at node $i, Y_{i}^{k l}=1$; otherwise, $Y_{i}^{k l}=0$.

$Z_{r}$ : 0-1 decision variable. If using container $\mathrm{r}, Z_{r}=1$; otherwise, $Z_{r}=0$.

The problem is formulated as follows:

$$
\begin{aligned}
& \min Z_{1}=\sum_{(i, j) \in A} \sum_{m} C_{i j}^{m} * X_{i j}^{m}+\sum_{k \in M} \sum_{i \in T_{r}} \sum_{l \in M} C_{i}^{k l} * y_{i}^{k l} \\
& \min Z_{2}=\sum_{(i, j) \in A} \sum_{m} \frac{d_{i j}^{m}}{V_{i j}^{m}} * X_{i j}^{m}+\sum_{i \in T_{r}} \sum_{k \in M} \sum_{l \in M} T_{i}^{k l} * Y_{i}^{k l} \\
& \min Z_{3}=\sum_{r \in R} C_{r} * Q * Z_{r}
\end{aligned}
$$

such that

$$
\begin{aligned}
& \sum_{h \in I} \sum_{m} X_{h i}^{m}-\sum_{j \in I} \sum_{m} X_{i j}^{m}=\left\{\begin{array}{c}
1 i=d \\
0 \forall i \in T_{r} \\
-1 i=o
\end{array}\right. \\
& \sum_{k \in M_{I}} \sum_{l \in M_{I}} Y_{i}^{k l} \leq 1 \forall(i, j) \in A \\
& \sum_{m \in M_{i j}} X_{i j}^{m} \leq 1 \forall(i, j) \in A \\
& \sum_{r} Z_{r}=1 \forall r \in R \\
& Z_{r} \leq \max \left\{X_{i j}^{m}\right\} \\
& \sum_{k \in M} Y_{i}^{k l}=\sum_{j \in M} X_{i j}^{l} \forall i \in T_{r} \forall l \in M_{I} \\
& \sum_{h \in I} X_{h i}^{k}=\sum_{l \in M} Y_{i}^{k l} \forall i \in T_{r} \forall k \in M_{I} \\
& \sum_{(i, j) \in A} \sum_{m \in M} \frac{d_{i j}^{m}}{V_{i j}^{m}} * X_{i j}^{m}+\sum_{i \in T_{r}} \sum_{k \in M} \sum_{l \in M} T_{i}^{k l} * Y_{i}^{k l} \leq T \\
& Z_{r} *\left\{\sum_{(i, j) \in A} \sum_{m \in M} \frac{d_{i j}^{m}}{V_{i j}^{m}} * X_{i j}^{m}+\sum_{i \in T_{r}} \sum_{k \in M} \sum_{l \in M} T_{i}^{k l} * Y_{i}^{k l}\right\} \leq \max \left\{T_{r}^{m} * X_{i, j}^{m}\right\} \forall r \in R \\
& X_{i j}^{m}=\left\{\begin{array}{l}
0 \\
1
\end{array} \quad \forall(i, j) \in A m \in M\right. \\
& Y_{i}^{k l}=\left\{\begin{array}{l}
0 \\
1
\end{array} \forall i \in T_{r} \quad \forall k \in M \forall l \in M\right.
\end{aligned}
$$




$$
\begin{gathered}
Z_{r}=\left\{\begin{array}{l}
0 \\
1
\end{array} \forall r \in R\right. \\
Y_{i}^{k l}=0 \forall i \in\{o, d\} \forall k \in M \forall l \in M
\end{gathered}
$$

The objective consists of three parts: Function (1) minimizes the total cost, which includes the transportation cost that is incurred in the arcs and the transshipment cost that is incurred at the nodes between transportation modes. Function (2) minimizes the total transportation time on the arcs and the transshipment time at the nodes between transportation modes. Function (3) minimizes the total cost of using containers. Constraint set (4) ensures the balance between the inbound and outbound flows at each node of the network. Constraint set (5) ensures that the consignment of goods will not be split into several sub-consignments during transport. Constraint set (6) specifies that only one mode of transportation can be used in a network arc. Constraint set (7) ensures that only one container is used in the multimodal network. Constraint set (8) is the corresponding relationship between the transportation mode and the container. Constraint sets (9) and (10) express the logical relationships between the decision variables. Constraint set (11) ensures that the total transportation time does not exceed the transit period of the goods. Constraint set (12) ensures that the total transportation time does not exceed the limited use time of the containers. Constraint sets (13)-(15) ensure that the decision variables are $0-1$ integers. Constraint set (16) ensures there is no transshipment at the origin node or the destination node.

\section{Solution Method}

The model presented in this paper is a multi-objective nonlinear integer programming model and the transportation cost and the transportation time are the two major optimization objectives. Unfortunately, there is a conflict between these two objectives; hence, we cannot minimize all objective functions simultaneously. According to previous research, Pareto optimality is a typically accepted solution to this problem.

To solve the multi-objective model, we use the normalized normal constraint method (NNCM) to obtain the Pareto solutions. This method was proposed by Messac and has been accepted and used by many scholars. According to Messac's description (16), this method is divided into seven steps:

\section{Step 1: ANCHOR POINTS}

We establish three single-objective problems named, P1, P2 and P3. The objective of P1 is to minimize total transportation costs $Z_{1}^{*}$ and the model consists of objective function (1) and constraints (4)-(16). The objective of P2 is to minimize the total transportation time $Z_{2}^{*}$ and the model consists of objective function (2) and constraints (4)-(16). The objective of P3 is to minimize the total use costs of containers $Z_{3}^{*}$ and the model consists of objective function (3) and constraints (4)-(16). Solving problem P1, P2 problem P3 independently and obtaining the optimal solutions of these three problems. Let $\mu^{1 *}=\left[x^{1 *}, y^{1 *}\right], \mu^{2 *}=\left[x^{2 *}, y^{2 *}\right], \mu^{3 *}=\left[x^{3 *}, y^{3 *}\right]$ represent the optimal solutions of problem P1, P2 and problem P3, respectively.

\section{Step 2: OBJECTIVE NORMALIZATION}

In order to obtain the required mapping parameters, we define the two points: the Utopia point $\mu^{N}$, which are evaluated as follows:

$$
\begin{gathered}
\mu^{N}=\left[\mu_{1}^{N}, \mu_{2}^{N}, \mu_{3}^{N}\right]^{T} \\
\mu_{i}^{N}=\max \left[\mu_{i}\left(x^{1 *}\right), \mu\left(x^{2 *}\right), \mu\left(x^{3 *}\right)\right]^{T}
\end{gathered}
$$

and the Nadir point $\mu^{u}$.

$$
\mu^{u}=\left[\mu_{i}\left(x^{1 *}\right), \mu\left(x^{2 *}\right), \mu\left(x^{3 *}\right)\right]^{T}
$$


The matrix $L$ is evaluated as follows:

$$
\text { Let } L=\left\{\begin{array}{l}
l_{1} \\
l_{2} \\
l_{3}
\end{array}\right\}=\mu^{N}-\mu^{u}
$$

Finally, the normalized form of vector $\mathrm{Z}$ can be evaluated as the following formula:

$$
\overline{Z_{i}}=\frac{\mu_{i}-\mu_{i}\left(x^{i *}\right)}{l_{i}}, i=1,2,3
$$

Step 3: UTOPIA LINE VECTOR CALCULATION

Taking $\overline{D_{k}}$ as the direction from $\overline{\mu^{k *}}$ to $\overline{\mu^{3 *}}$ for $k \in\{1,2\}$ then:

$$
\overline{D_{k}}=\bar{\mu}^{3 *}-\bar{\mu}^{k *}
$$

\section{Step 4: NORMALIZED INCREMENT DEFINITION}

As we know, Pareto is a solution set. If the normalized increment $\delta_{k}$ along the direction $\overline{D_{k}}$ consists of $m_{k}$ prescribed number of solutions, $\delta_{k}$ can be defined as follows:

$$
\delta_{k}=\frac{1}{m_{k}-1}, 1 \leq k \leq 2
$$

Among them,

$$
m_{k}=\frac{m_{1 *}\left\|\overline{D_{k}}\right\|}{\left\|\overline{D_{1}}\right\|}
$$

\section{Step 5: UTOPIA LINE POINT GENERATION}

The points evenly distributed on the utopia hyperplane can be obtained by the following equation:

$$
\bar{x}_{p j}=\alpha_{1 j} * \bar{\mu}^{1 *}+\alpha_{2 j} * \bar{\mu}^{2 *}+\alpha_{3 j} * \bar{\mu}^{3 *}
$$

Among which,

$$
\begin{gathered}
0 \leq \alpha_{1 j} \leq 1 \forall j \in\{1,2, \cdots m\} \\
0 \leq \alpha_{2 j} \leq 1 \forall j \in\{1,2, \cdots m\} \\
0 \leq \alpha_{3 j} \leq 1 \forall j \in\{1,2, \cdots m\} \\
\sum_{k=1}^{3} \alpha_{k j}=1
\end{gathered}
$$

The generation of these points is shown in the following Figure 1:

\section{Step 6: PARETO POINT GENERATION}

The point set $\bar{x}_{p j}$ we obtained on the utopia hyperplane from step 5 corresponding to the Pareto solutions. The solution formula is as follows:

$\operatorname{Min} \overline{Z_{n}^{*}}$

s.t. Equations (4)-(16)

$$
\begin{gathered}
x_{l i} \leq x_{i} \leq x_{u i}, 1 \leq i \leq 3 \\
\overline{D_{k}} *\left(\bar{Z}-\bar{x}_{p j}\right)^{T} \leq 0,1 \leq k \leq 2
\end{gathered}
$$




$$
\overline{Z_{i}}=\frac{\mu_{i}-\mu_{i}\left(x^{i *}\right)}{l_{i}}, i=1,2,3
$$

\section{Step 7: PARETO DESIGN METRIC VALUE DETERMINATION}

After the Pareto points have been identified, the solution points are substituted into the objective function equation and the corresponding values of the multi-objective model are obtained.

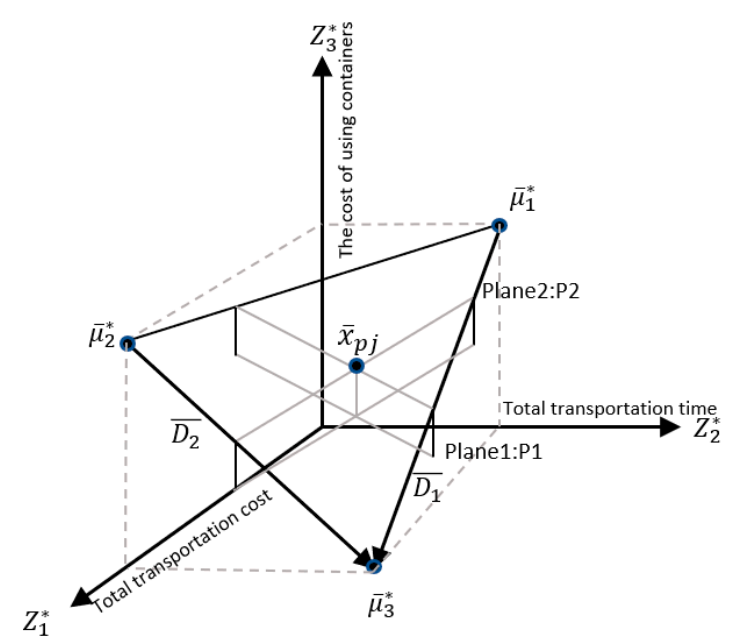

(a)

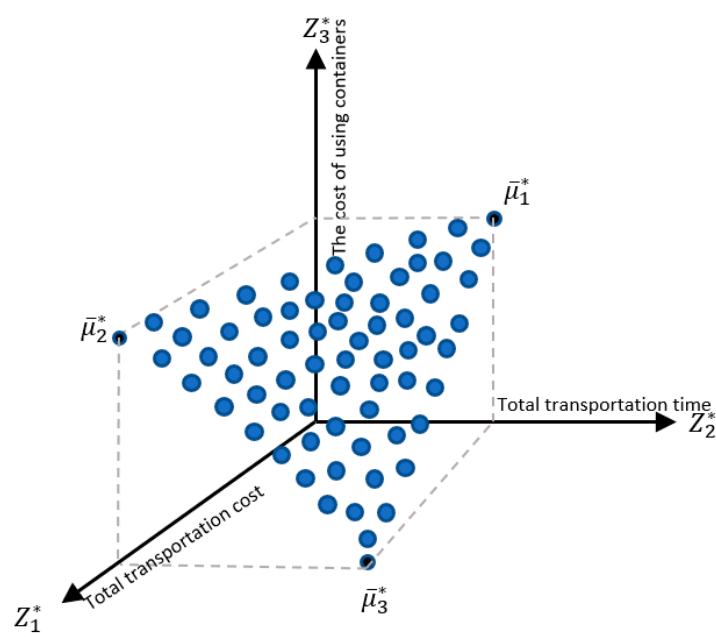

(b)

Figure 1. Utopia hyperplane points generated in a three-objective modal. (a) Utopia hyperplane for a three-objective modal with (b) evenly-spaced points on the utopia hyperplane.

\section{Case Study}

\subsection{Case Design}

The large demand for the export of vanadium iron ore in Panzhihua city, which is located in the southwest of China, has led to the establishment of many freight forwarders, of which Decheng freight company of Sichuan province is a typical representative. This company performs a complete set of service functions, such as freight forwarding, booking, customs declaration, agent inspection, highway transportation, tallying, warehousing, agent insurance and modern integrated logistics, and undertakes domestic and international freight transportation via rail, sea, river, land and air multimodal transport. To more effectively complete the freight service, the company has established its own logistics transportation network. The company's vanadium iron ore export transport network is illustrated in Figure 2 below.

Using the navigation resource of the Yangtze river, the vanadium iron ore of Panzhihua can be transported to Nanjing and Shanghai via Chengdu, Wuhan and other important railway and port hubs. In this transportation network, there are three modes of transportation: railway, waterway and highway. The average speeds of these three transportation modes were obtained from Zhao's study [31] and are listed in Table 1.

Table 1. Container Transportation Speeds of the Three Transportation Modes.

\begin{tabular}{cc}
\hline Transportation Mode & Speed \\
\hline Train & $65 \mathrm{~km} / \mathrm{h}$ \\
\hline Highway & $85 \mathrm{~km} / \mathrm{h}$ \\
\hline Water & $25 \mathrm{~km} / \mathrm{h}$ \\
\hline
\end{tabular}




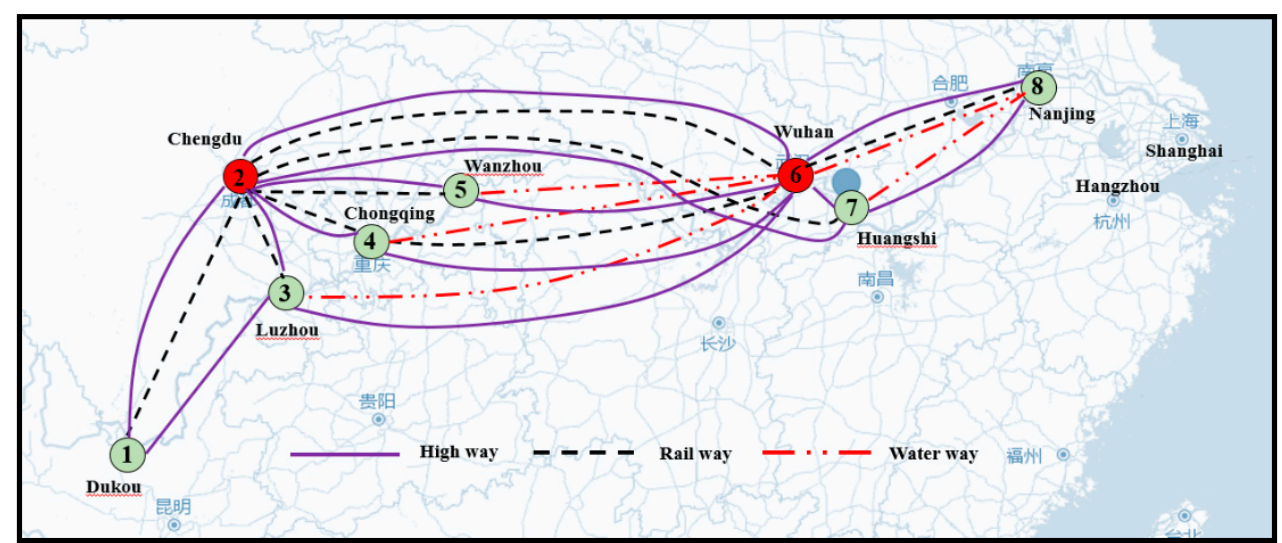

(a)

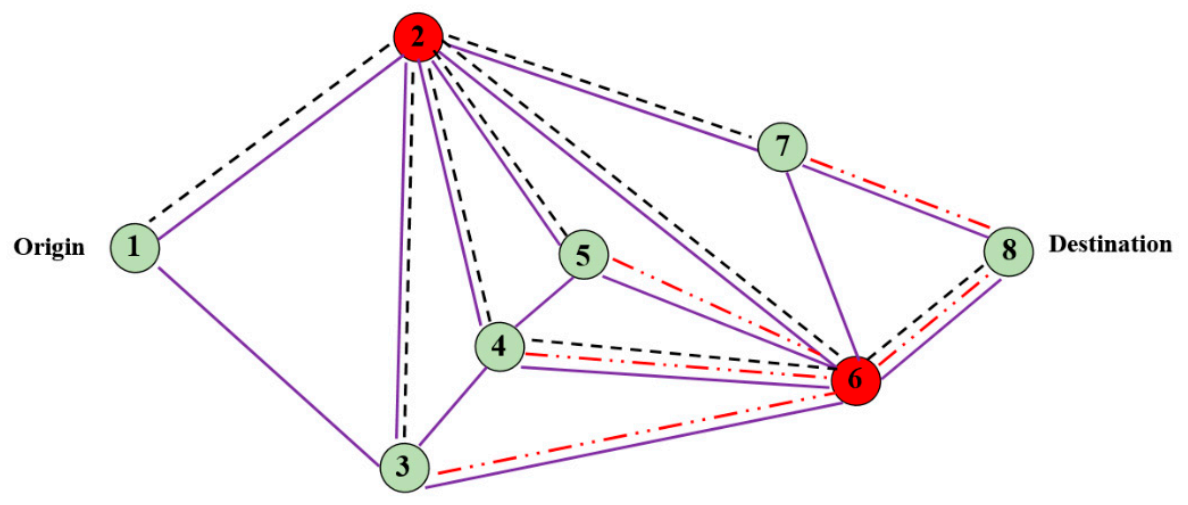

(b)

Figure 2. Transport network diagram. (a) Transport network of case and (b) transportation network topology.

In China, railway transportation is managed by the Ministry of Railways and the unit transport cost of railway can be obtained from the freight information network platform of the Ministry of Railways. After logging onto the official website (http://www.95306.cn/) and specifying the type of goods and the origin and destination, the unit transport cost of railway containers between the two stations is displayed. The unit transport costs for highway and water are obtained from the real-time dynamic-updating freight website http://www.jctrans.com/, the distances between pairs of points in the network are obtained from Auto Navi Map and the enterprise investigation of Decheng freight company. Table 2 lists the unit transport costs and the transportation distance of the three modes of transport.

Since the cost of transshipment between modes is difficult to estimate, the transshipment costs and times that are used in this paper are obtained mainly from the research of Sun and Lang [18] and the investigation of Decheng freight company, as shown in Table 3.

To solve the problem of limited container resources, the freight company can rent containers from railway stations and shipping companies. However, according to the regulations of the Sichuan Railway Administration, railway containers are subject to strict limitations on the use time, which are listed in Table 4. Considering the loss of containers and the cost of purchase, it is impossible for freight companies to buy new containers every time when they transport goods. Therefore, we set the cost of using company own containers as the current sale price of second-hand containers in the region. According to the market situation of China's second-hand container market, the use price of enterprises' own containers is positioned at 947.07 USD/TEU. In addition, according to the regulations, the transport prices of different sizes containers are different, and the charging items in the process of container transportation include transportation fees, handling fees, warehousing fees, etc. 
Among them, instead of charging separately for the use of containers, the purchase cost and loss of containers are divided into specific operating charges such as transportation, handling, storage and so on. Similar to railway containers, the cost of shipping company containers is included in various processes, not charged separately. Since the use cost of railway containers and shipping company containers is included in the transport cost, the cost of these two containers is positioned symbolically at $1.39 \mathrm{USD} / \mathrm{TEU}$ and $2.08 \mathrm{USD} / \mathrm{TEU}$.

Table 2. Unit Costs and Transportation Distance of Three Transportation Modes on the Arcs.

\begin{tabular}{ccccccc}
\hline \multirow{2}{*}{ Arc } & \multicolumn{2}{c}{ Rail } & \multicolumn{2}{c}{ Water } & \multicolumn{2}{c}{ Road } \\
\cline { 2 - 7 } & $\begin{array}{c}\text { Cost } \\
\text { (USD/TEU) }\end{array}$ & $\begin{array}{c}\text { Distance } \\
\mathbf{( k m )}\end{array}$ & $\begin{array}{c}\text { Cost } \\
\text { (USD/TEU) }\end{array}$ & $\begin{array}{c}\text { Distance } \\
\mathbf{( k m )}\end{array}$ & $\begin{array}{c}\text { Cost } \\
\text { (USD/TEU) }\end{array}$ & $\begin{array}{c}\text { Distance } \\
\mathbf{( k m )}\end{array}$ \\
\hline $\mathbf{( 1 , 2 )}$ & 485.40 & 2762.5 & - & - & 835.65 & 694.2 \\
\hline $\mathbf{( 1 , 3 )}$ & - & - & - & - & 1880.22 & 816.8 \\
\hline $\mathbf{( 2 , 3 )}$ & 231.55 & 650 & - & - & 1086.35 & 288.1 \\
\hline $\mathbf{( 2 , 4 )}$ & 353.15 & 975 & - & - & 1169.92 & 280.2 \\
\hline $\mathbf{( 2 , 5 )}$ & 370.56 & 975 & - & - & 1253.48 & 471.2 \\
\hline $\mathbf{( 2 , 6 )}$ & 793.68 & 1787.5 & - & - & 1545.96 & 1130.6 \\
\hline $\mathbf{( 2 , 7 )}$ & 862.26 & 2275 & - & - & 1671.31 & 1249 \\
\hline $\mathbf{( 3 , 4 )}$ & - & - & - & - & 1378.83 & 178.3 \\
\hline $\mathbf{( 3 , 6 )}$ & - & - & 116.99 & 1680 & 1378.83 & 1010.6 \\
\hline $\mathbf{( 4 , 5 )}$ & - & - & - & - & 1253.48 & 310.7 \\
\hline $\mathbf{( 4 , 6 )}$ & 697.73 & 1462.5 & 88.72 & 1274 & 1671.31 & 889.6 \\
\hline $\mathbf{( 5 , 6 )}$ & - & - & 65.95 & 947 & 1253.48 & 669 \\
\hline $\mathbf{( 6 , 7 )}$ & - & - & - & - & 626.74 & 119.4 \\
\hline $\mathbf{( 6 , 8 )}$ & 426.13 & 812.5 & 51.04 & 733 & 1253.48 & 524.1 \\
\hline $\mathbf{( 7 , 8 )}$ & - & - & 41.09 & 590 & 1504.18 & 522.7 \\
\hline & & & & & & \\
\hline
\end{tabular}

Table 3. Costs of Transferring between Transportation Modes.

\begin{tabular}{cccc}
\hline Cost: USD (Time: $h)$ & Train & Water & Highway \\
\hline Train & $0(0)$ & $142(12)$ & $63(6)$ \\
\hline Water & $142(12)$ & $0(0)$ & $120(8)$ \\
\hline Highway & $63(6)$ & $120(8)$ & $0(0)$ \\
\hline
\end{tabular}

Table 4. Limited Use Times of Containers under Three Transportation Modes.

\begin{tabular}{cccc}
\hline Containers (h) & Train & Water & Highway \\
\hline Railway & 168 & 288 & 168 \\
\hline Self & - & - & - \\
\hline Water & - & - & - \\
\hline
\end{tabular}

\subsection{Solution and Sensitivity Analysis}

\subsubsection{Solution of the Case Study}

In China, parcels typically arrive in three days. However, freight products take longer to transport. Considering the time of transport via water, we set the transportation time to $120 \mathrm{~h}$ in this case. Using the NNCM, which is proposed in the fourth part of this paper, we obtained a set of six Pareto solutions, 
which are listed in the Table 5 below. All solutions in this paper are obtained on a laptop computer using CPLEX software.

Table 5. Pareto set of the case study using CPLEX software.

\begin{tabular}{ccccccc}
\hline Container & Route & Mode & $\begin{array}{c}\text { Transportation } \\
\text { Time (h) }\end{array}$ & $\begin{array}{c}\text { Container } \\
\text { Cost (USD) }\end{array}$ & $\begin{array}{c}\text { Transportation } \\
\text { Cost (USD) }\end{array}$ \\
\hline 1 & Self & $1-2-6-8$ & Road-Road-Road & 30.40 & 9470.75 & 173,000 \\
\hline 2 & Water & $1-2-6-7-8$ & Road-Road-Road-Water & 57.10 & 20.89 & 145,000 \\
\hline 3 & Water & $1-2-7-8$ & Road-Road-Water & 58.00 & 20.89 & 121,000 \\
\hline 4 & Railway & $1-2-6-8$ & Road-Rail-Water & 84.22 & 13.93 & 50,300 \\
\hline 5 & Railway & $1-2-6-7-8$ & Rail-Rail-Road-Water & 109.70 & 13.93 & 44,800 \\
\hline 6 & Railway & $1-2-6-8$ & Rail-Rail-Water & 111.32 & 13.93 & 14,800 \\
\hline
\end{tabular}

If the total transportation time is relatively small, freight forwarders prefer to choose their own containers. The shorter the transport restriction time, the fewer alternative transport routes. In extreme cases, when all routes are highways, freight companies cannot use railway containers or a ship company's containers; hence, they must use their own containers, which will generate huge container usage costs. With the relaxation of the transportation time, freight companies have more alternative transport routes. In this scenario, railways and waterways will be incorporated into the routes to create conditions in which freight companies can use railway containers and a ship company's containers. The higher the transportation cost is, the more inclined freight companies are to use their own containers. According to Table 5, the transportation route that is associated with the highest transportation cost is road-only transportation, in which freight companies cannot use railway containers and water containers. With the use of railway and water containers in the transportation process, transportation costs gradually decrease while opening the door for freight companies to choose such containers.

According to Figure 3, the transportation cost and the transportation time are negatively correlated. The transportation speed of highways is the fastest but the cost is the highest. The shorter the total transportation time, the higher the probability of choosing road transportation and, therefore, the higher the total transportation cost. With the increase in the transportation time, railway and water transport modes become more likely to be selected, which will substantially reduce the transportation costs. Moreover, the multimodal transportation of highway, railway and water can balance the transportation time and cost and ultimately maximize the economic benefits. Comparing with Sun and Lang [18] shown in Figure $3 c$, we found that the change curves of the two studies are in the same direction, which proved the reliability of our model and solution.

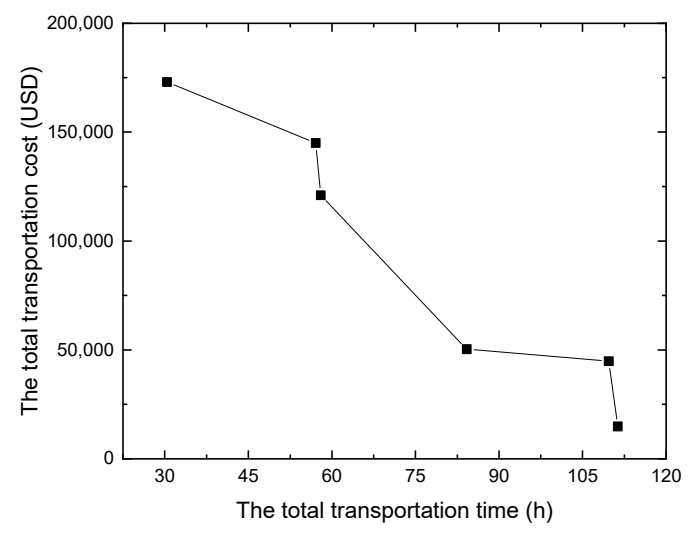

(a)

Figure 3. Cont. 


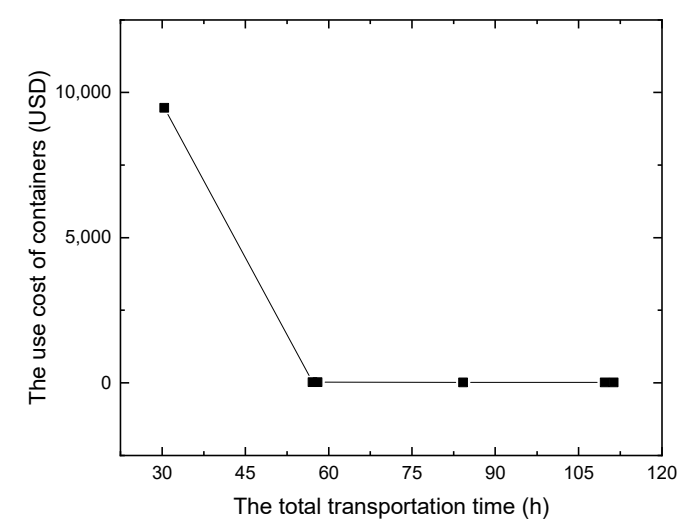

(b)

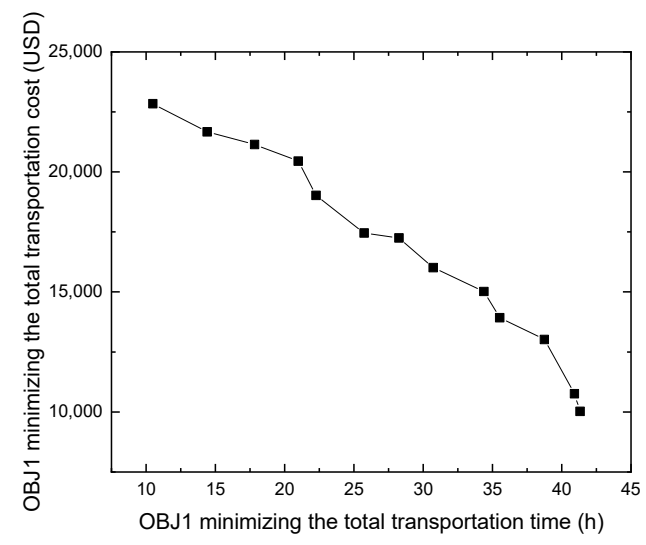

(c)

Figure 3. Objectives of transportation time and transportation cost. (a) The relationship between total transportation time and total transportation cost, (b) the relationship between total transportation time and the use cost of containers, and (c) control group.

\subsubsection{Sensitivity Analysis of the Transportation Time Limit}

For this multi-objective problem, we used the NNCM to obtain the Pareto solutions. In this part, we set the number of Pareto solutions $(\mathrm{m})$ as 3 and choose the intermediate solutions of the set as the final solutions when we changed the transportation time limit $T$. We considered 15 values of the transportation time limit $\mathrm{T}$ and obtained the corresponding solutions, which are listed in Table 6.

When the total transportation time is limited to less than $30 \mathrm{~h}$, there is no available transport route in the transport network. Similarly, regardless of which type of container is selected, it is impossible to satisfy the transportation time limit. Over time, more alternative routes and containers become available. Self-owned containers are rarely selected. Railway and water transport are adopted when the transportation time permits, which provides conditions for the use of railway containers and water containers, while reducing the need to use self-owned containers.

According to Figure 4, changing the total transport time limit results in corresponding changes in the transport schemes. The choice of containers also changes. However, when the transport time is limited to a specified range, the transport plan does not change. For example, when the transportation time limit ranges from 60 to $84 \mathrm{~h}$, the optimal route solution is 1-2-6-7 and the multimodal transport mode is Road-Road-Water. When the transportation time limit exceeds $84 \mathrm{~h}$, the optimal multimodal transport mode changes to Road-Rail-Water and the selection of containers changes from ship company containers to railway containers. According to the solution, each scheme has a suitable transportation time range. We fixed the size of the Pareto solution set and select one solution from the Pareto solution 
set as the optimal solution under these data. From the perspective of the solution method, it has directivity. In addition, we built a discrete model in which the transport scheme and the objective function of each group of solutions are independent of each other and there will be numerical differences between the discrete solutions. When a transportation time limit falls within this range, there is no corresponding solution in the network; hence, the solution with the smallest difference is selected as the optimal solution. Therefore, the scope of use of each transport scheme is limited. When the transportation time limit is relaxed sufficiently, the network time constraint is removed. In this case, only the transportation cost is considered in the optimization objective and the network will eventually form a stable optimal solution. In the case that is examined in this paper, when the transportation time limit exceeds $84.22 \mathrm{~h}$, the final optimization solution of the route selection scheme is available-that is, when the shipper's time limit exceeds $84 \mathrm{~h}$, the best method of transport for freight forwarders is to use railway containers and route 1-2-6-8 under multimodal transport mode Road-Rail-Water.

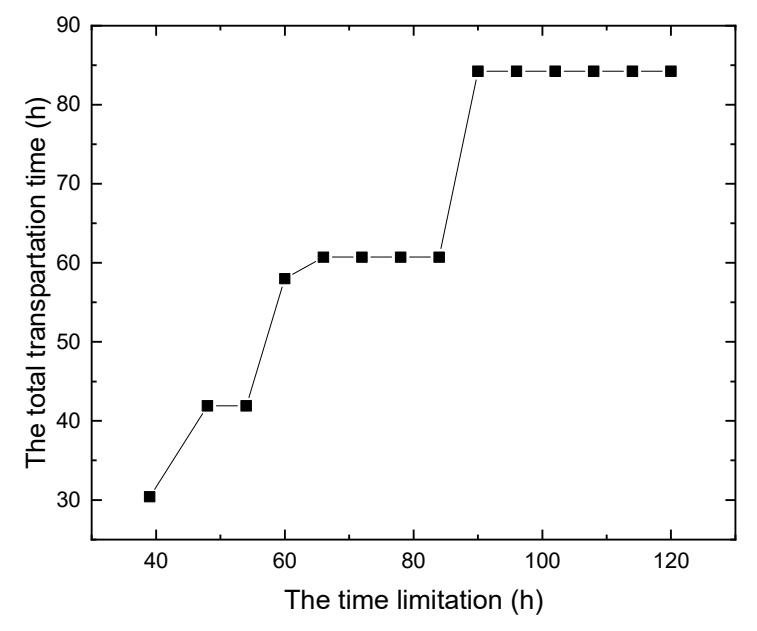

(a)

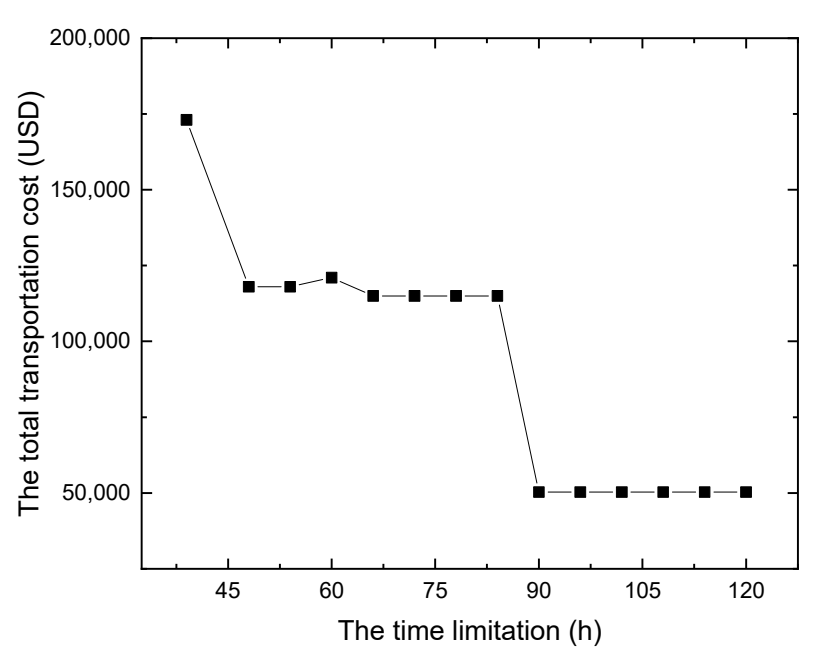

(b)

Figure 4. Objectives of transportation time and transportation cost under different time limits. (a) The relationship between time limitation and the total transportation time and $(\mathbf{b})$ the relationship between time limitation and the total transportation cost. 
Table 6. Solutions under Various Transportation Time Limits.

\begin{tabular}{cccccccc}
\hline & $\begin{array}{c}\text { Time } \\
\text { Limit } \mathbf{( h )}\end{array}$ & Container & Route & Mode & $\begin{array}{c}\text { Transportation } \\
\text { Time (h) }\end{array}$ & $\begin{array}{c}\text { Container } \\
\text { Cost (USD) }\end{array}$ & $\begin{array}{c}\text { Transportation } \\
\text { Cost (USD) }\end{array}$ \\
\hline 1 & 30 & - & - & - & - & - & - \\
\hline 2 & 39 & Self & $1-2-6-8$ & Road-Road-Road & 30.4 & 9470.75 & 173,000 \\
\hline 3 & 48 & Railway & $1-2-6-8$ & Road-Road-Rail & 41.9 & 13.93 & 118,000 \\
\hline 4 & 54 & Railway & $1-2-6-8$ & Road-Road-Rail & 41.9 & 13.93 & 118,000 \\
\hline 5 & 60 & Ship & $1-2-7-8$ & Road-Road-Water & 58 & 20.89 & 121,000 \\
\hline 6 & 66 & Ship & $1-2-6-8$ & Road-Road-Water & 60.72 & 20.89 & 115,000 \\
\hline 7 & 72 & Ship & $1-2-6-8$ & Road-Road-Water & 60.72 & 20.89 & 115,000 \\
\hline 8 & 78 & Ship & $1-2-6-8$ & Road-Road-Water & 60.72 & 20.89 & 115,000 \\
\hline 9 & 84 & Ship & $1-2-6-8$ & Road-Road-Water & 60.72 & 20.89 & 115,000 \\
\hline 10 & 90 & Railway & $1-2-6-8$ & Road-Rail-Water & 84.22 & 13.93 & 50,300 \\
\hline 11 & 96 & Railway & $1-2-6-8$ & Road-Rail-Water & 84.22 & 13.93 & 50,300 \\
\hline 12 & 102 & Railway & $1-2-6-8$ & Road-Rail-Water & 84.22 & 13.93 & 50,300 \\
\hline 13 & 108 & Railway & $1-2-6-8$ & Road-Rail-Water & 84.22 & 13.93 & 50,300 \\
\hline 14 & 114 & Railway & $1-2-6-8$ & Road-Rail-Water & 84.22 & 13.93 & 50,300 \\
\hline 15 & 120 & Railway & $1-2-6-8$ & Road-Rail-Water & 84.22 & 13.93 & 50,300 \\
\hline
\end{tabular}

\subsubsection{Sensitivity Analysis of the Use Time Limits of Containers}

In practice, due to the management of the Ministry of Railways, the use conditions of railway containers are more stringent. Hence, it is necessary to study the influence of the change of the railway containers' use time on the route choice. We set the transportation time limit to $120 \mathrm{~h}$ in this case and use the same calculation method as in part 2 to obtain the optimal solutions. Then, the service time of railway containers under one mode is changed while those of the other two modes of transport remain unchanged. The solutions are presented in Table 7.

Table 7. Objectives of transportation time and transportation cost.

\begin{tabular}{|c|c|c|c|c|c|c|c|c|}
\hline & Mode & $\begin{array}{c}\text { Time } \\
\text { Limit (h) }\end{array}$ & Container & Route & Mode & $\begin{array}{l}\text { Transportation } \\
\text { Time (h) }\end{array}$ & $\begin{array}{l}\text { Container } \\
\text { Cost (USD) }\end{array}$ & $\begin{array}{c}\text { Transportation } \\
\text { Cost (USD) }\end{array}$ \\
\hline 1 & \multirow{5}{*}{ Road } & 48 & Ship & $1-2-6-8$ & Road-Rail-Water & 84.22 & 20.89 & 50,300 \\
\hline 2 & & 72 & Ship & $1-2-6-8$ & Road-Rail-Water & 84.22 & 20.89 & 50,300 \\
\hline 3 & & 84 & Ship & $1-2-6-8$ & Road-Rail-Water & 84.22 & 20.89 & 50,300 \\
\hline 4 & & 96 & Railway & $1-2-6-8$ & Road-Rail-Water & 84.22 & 13.93 & 50,300 \\
\hline 5 & & 108 & Railway & $1-2-6-8$ & Road-Rail-Water & 84.22 & 13.93 & 50,300 \\
\hline 6 & \multirow{5}{*}{ Rail } & 48 & Ship & $1-2-6-8$ & Road-Rail-Water & 84.22 & 20.89 & 50,300 \\
\hline 7 & & 72 & Ship & $1-2-6-8$ & Road-Rail-Water & 84.22 & 20.89 & 50,300 \\
\hline 8 & & 84 & Ship & $1-2-6-8$ & Road-Rail-Water & 84.22 & 20.89 & 50,300 \\
\hline 9 & & 96 & Railway & $1-2-6-8$ & Road-Rail-Water & 84.22 & 13.93 & 50,300 \\
\hline 10 & & 108 & Railway & $1-2-6-8$ & Road-Rail-Water & 84.22 & 13.93 & 50,300 \\
\hline 11 & \multirow{5}{*}{ Water } & 48 & Ship & $1-2-6-8$ & Road-Rail-Water & 84.22 & 20.89 & 50,300 \\
\hline 12 & & 72 & Ship & $1-2-6-8$ & Road-Rail-Water & 84.22 & 20.89 & 50,300 \\
\hline 13 & & 84 & Ship & $1-2-6-8$ & Road-Rail-Water & 84.22 & 20.89 & 50,300 \\
\hline 14 & & 96 & Railway & $1-2-6-8$ & Road-Rail-Water & 84.22 & 13.93 & 50,300 \\
\hline 15 & & 108 & Railway & $1-2-6-8$ & Road-Rail-Water & 84.22 & 13.93 & 50,300 \\
\hline
\end{tabular}

With the change in the time limit for the railway containers, the multimodal transport scheme does not change. However, the container selection does change. Although the railway transport mode is selected in the optimal scheme, railway containers remain unavailable under various time constraints. Regardless of the mode of transportation, when using a time limit of containers that is 
less than $84.22 \mathrm{~h}$, no railway containers are available, and the final result is the selection of shipping containers. By comparison with Table 7, we found that compared with the use time limit of containers, the total transport time limit has a larger impact on the choice of the optimal route. The container use time restriction has a larger influence on the selection of containers and a smaller influence on the choice of the optimal route.

\section{Conclusions}

Under the guidance of China's "one belt and one road" economic strategy, multimodal transport ushered in vast potential for development, which has spawned many multimodal freight forwarding enterprises. To overcome the shortage of containers that is faced by freight forwarders in the transportation process, they must consider the source of the containers and use railway containers and shipping company containers. However, the use of containers is related to the choice of routes. If freight forwarders want to use railway containers or shipping company containers, then they must choose railway or water transportation accordingly.

We developed an optimization model for multimodal transport route selection, in which the interrelationship between container and route selection is considered, along with the time limit on container usage. The objective function of the model minimizes the total transportation cost, the transportation time and the container use cost. To solve this multi-objective problem, we used the NNCM to obtain the Pareto solutions. Considering the transportation of Panzhihua iron ore in Sichuan province as an example, we conduct a case study. According to our analysis, when facing a shortage of containers, freight companies should choose railway transportation as frequently as possible and use railway containers at the same time, which most effectively balances the transportation time and cost and overcomes the shortage of containers.

In this paper, we investigated the route selection problem of multimodal transportation in which the source of the containers is considered. Overall, this path selection model is a deterministic optimization model. However, in practice, a multimodal transport system is a complex transport system that involves many transport links, which produce substantial uncertainties. For example, due to the overloading of the Yangtze River, cargo shipments often must wait in line, which leads to unpredictable transport times. Therefore, we suggest considering uncertainty in transport times as an area of future study.

Author Contributions: D.C., Y.Z. and R.G.T. proposed the research concept and designed the paper framework; D.C. collected the data and established the mathematical model; D.C. and L.G. completed the solution and analysis of the model; D.C. prepared the draft manuscript.

Funding: This research was funded by [Science and Technology Demonstration Project of Multimodal Freight Transport in Jiangsu Province] grant number [2018Y02] And [Technology Program of Fujian University of Technology] grant number [GY-Z17155].

Conflicts of Interest: The authors declare no conflict of interest. The founding sponsors had no role in the design of the study; in the collection, analyses, or interpretation of data; in the writing of the manuscript, and in the decision to publish the results.

\section{References}

1. Wei, W.; Chang, J.S. Integrated Algal Biorefineries from Process Systems Engineering Aspects: A Review. Bioresour. Technol. 2019, 291, 121939.

2. SteadieSeifi, M.; Dellaert, N.P.; Nuijten, W.; Van Woensel, T.; Raoufi, R. Multimodal Freight Transportation Planning: A Literature Review. Eur. J. Oper. Res. 2014, 233, 1-15. [CrossRef]

3. State Council of China. Long-term Planning for the Development of Logistic Industry (2014-2020). China Transp. Rev. 2014, 10, 33-40.

4. Giusti, R.; Iorfida, C.; Li, Y.; Manerba, D.; Musso, S.; Perboli, G.; Tadei, R.; Yuan, S. Sustainable and De-stressed International Supply-chains through the SYNCHRO-NET Approach. Sustainability 2019, 11, 1083. [CrossRef]

5. Perboli, G.; Musso, S.; Rosano, M.; Tadei, R.; Godel, M. Synchro-modality and Slow Steaming: New Business Perspectives in Freight Transportation. Sustainability 2017, 9, 1843. [CrossRef] 
6. Hertz, S.; Alfredsson, M. Strategic Development of Third Party Logistics Providers. Ind. Mark. Manag. 2003, 32, 139-149. [CrossRef]

7. Li, J.A.; Liu, K.; Leung, S.C.; Lai, K.K. Empty Container Management in a Port with Long-run Average Criterion. Math. Comput. Model. 2004, 40, 85-100. [CrossRef]

8. Braekers, K.; Janssens, G.K.; Caris, A. Challenges in Managing Empty Container Movements at Multiple Planning Levels. Transp. Rev. 2011, 31, 681-708. [CrossRef]

9. Moskalyk, R.; Alfantazi, R. Processing of Vanadium: A Review. Miner. Eng. 2003, 16, 793-805. [CrossRef]

10. Crainic, T.G.; Gendreau, M.; Dejax, P. Dynamic and Stochastic Models for the Allocation of Empty Containers. Oper. Res. 1993, 41, 102-126. [CrossRef]

11. Beresford, A.; Pettit, S.; Xu, Q.; Williams, S. A Study of Dry Port Development in China. Marit. Econ. Logist. 2012, 14, 73-98. [CrossRef]

12. Wang, L.; Zhu, X.N.; Xie, Z.Y. Container Assignment Optimization Considering Overlapping Amount and Operation Distance in Rail-road Transshipment Terminal. Adv. Prod. Eng. Manag. 2017, 12, 363-374. [CrossRef]

13. Barnhart, C.; Ratlift, H.D. Modeling Multimodal Routing. J. Bus. Logist. 1993, 14, $206-223$.

14. Chang, T.S. Best Routes Selection in International Multimodal Networks. Comput. Oper. Res. 2008, 35, 2877-2891. [CrossRef]

15. Xiong, G.; Wang, Y. Best Routes Selection in Multimodal Networks Using Multi-objective Genetic Algorithm. J. Comb. Optim. 2014, 28, 655-673. [CrossRef]

16. Ayar, B.; Yaman, H. An Multimodal Multicommodity Routing Problem with Scheduled Services. Comput. Optim. Appl. 2011, 53, 131-153. [CrossRef]

17. Moccia, L.; Cordeau, J.F.; Laporte, G.; Ropke, S.; Valentini, M.P. Modeling and Solving a Multimodal Transportation Problem with Flexible-time and Scheduled Services. Networks 2011, 57, 53-68. [CrossRef]

18. Sun, Y.; Lang, M. Bi-objective Optimization for Multi-modal Transportation Routing Planning Problem Based on Pareto Optimality. J. Ind. Eng. Manag. 2015, 8, 1195-1217. [CrossRef]

19. Kim, H.J.; Chang, Y.T.; Lee, P.T.; Shin, S.H.; Kim, M.J. Optimizing the transportation of international container cargoes in Korea. Marit. Policy Manag. 2008, 35, 103-122. [CrossRef]

20. Sun, Y.; Lang, M. Modeling the Multicommodity Multimodal Routing Problem with Schedule-Based Services and Carbon Dioxide Emission Costs. Math. Probl. Eng. 2015, 2015, 406218. [CrossRef]

21. Sun, C.; Cheng, L.; Zhu, S.; Han, F.; Chu, Z. Multi-criteria User Equilibrium Model Considering Travel Time, Travel Time Reliability and Distance. Transp. Res. Part D 2019, 66, 3-12. [CrossRef]

22. Yong, Z.; Jiang, Y. Robust Optimization on Sustainable Biodiesel Supply Chain Produced from Waste Cooking Oil under Price Uncertainty. Waste Manag. 2016, 60, 329-339.

23. Qixiu, C.; Liu, Z.; Szeto, W.Y. A Cell-based Dynamic Congestion Pricing Scheme Considering Travel Distance and Time Delay. Transp. B 2019, 7, 1286-1304.

24. Fazayeli, S.; Eydi, A.; Kamalabadi, I.N. Location-routing Problem in Multimodal Transportation Network with Time Windows and Fuzzy Demands: Presenting a Two-part Genetic Algorithm. Comput. Ind. Eng. 2018, 119, 233-246. [CrossRef]

25. Sun, Y.; Lang, M.; Wang, J. On Solving the Fuzzy Customer Information Problem in Multicommodity Multimodal Routing with Schedule-Based Services. Information 2016, 7, 13. [CrossRef]

26. Tian, W.; Cao, C. A Generalized Interval Fuzzy Mixed Integer Programming Model for a Multimodal Transportation Problem under Uncertainty. Eng. Optim. 2016, 49, 481-498. [CrossRef]

27. Sun, Y.; Liang, X.; Li, X.; Zhang, C. A Fuzzy Programming Method for Modeling Demand Uncertainty in the Capacitated Road-Rail Multimodal Routing Problem with Time Windows. Symmetry 2019, 11, 91. [CrossRef]

28. Cao, C.; Gao, Z.; Li, K. Capacity Allocation Problem with Random Demands for the Rail Container Carrier. Eur. J. Oper. Res. 2012, 217, 214-221. [CrossRef]

29. Dong, J.X.; Lee, C.Y.; Song, D.P. Joint Service Capacity Planning and Dynamic Container Routing in Shipping Network with Uncertain Demands. Transp. Res. Part B Methodol. 2015, 78, 404-421. [CrossRef]

30. Meng, Q.; Wang, T.; Wang, S. Short-term Liner Ship Fleet Planning with Container Transshipment and Uncertain Container Shipment Demand. Eur. J. Oper. Res. 2012, 223, 96-105. [CrossRef]

31. Zhao, Y.; Liu, R.; Zhang, X.; Whiteing, A. A Chance-constrained Stochastic Approach to Multimodal Container Routing Problems. PLoS ONE 2018, 13, e0192275. 
32. Rouky, N.; Boukachour, J.; Boudebous, D.; Alaoui, A.E. A Robust Metaheuristic for the Rail Shuttle Routing Problem with Uncertainty: A Real Case Study in the Le Havre Port. Asian J. Shipp. Logist. 2018, 34, 171-187. [CrossRef]

33. Sun, Y.; Hrušovský, M.; Zhang, C.; Lang, M. A Time-Dependent Fuzzy Programming Approach for the Green Multimodal Routing Problem with Rail Service Capacity Uncertainty and Road Traffic Congestion. Complexity 2018, 2018, 8645793. [CrossRef]

34. Sun, Y.; Zhang, G.; Hong, Z.; Dong, K. How Uncertain Information on Service Capacity Influences the Multimodal Routing Decision: A Fuzzy Programming Perspective. Information 2018, 9, 24. [CrossRef]

35. Yang, L.; Gao, Z.; Li, X.; Li, K. A Weighted Min-Max Model for Balanced Freight Train Routing Problem with Fuzzy Information. Eng. Optim. 2011, 43, 1-21. [CrossRef]

36. Min, H.; Jayaraman, V.; Srivastava, R. Combined Location-routing Problems: A Synthesis and Future Research Directions. Eur. J. Oper. Res. 1998, 108, 1-15. [CrossRef]

37. Dukkanci, O.; Kara, B.Y. Routing and Scheduling Decisions in the Hierarchical Hub Location Problem. Comput. Oper. Res. 2017, 85, 45-57. [CrossRef]

38. Gharavani, M.; Setak, M. A Capacitated Location Routing Problem with Semi Soft Time Windows. Adv. Comput. Tech. Electromagn. 2015, 1, 26-40. [CrossRef]

39. Hiassat, A.; Diabat, A.; Rahwan, I. A Genetic Algorithm Approach for Location-inventory-routing Problem with Perishable Products. J. Manuf. Syst. 2017, 42, 93-103. [CrossRef]

40. Hrušovský, M.; Demir, E.; Jammernegg, W.; Van Woensel, T. Hybrid Simulation and Optimization Approach for Green Multimodal Transportation Problem with Travel Time Uncertainty. Flex. Serv. Manuf. J. 2016, 30, 486-516. [CrossRef]

41. Meng, Q.; Wang, S.; Andersson, H.; Thun, K. Containership Routing and Scheduling in Liner Shipping: Overview and Future Research Directions. Transp. Sci. 2015, 48, 265-280. [CrossRef]

42. Jeong, Y.; Saha, S.; Chatterjee, D.; Moon, I. Direct Shipping Service Routes with an Empty Container Management Strategy. Transp. Res. Part E 2018, 118, 123-142. [CrossRef]

43. Kolar, P.; Schramm, H.J.; Prockl, G. Intermodal Transport and Repositioning of Empty Containers in Central and Eastern Europe Hinterland. J. Transp. Geogr. 2018, 69, 73-82. [CrossRef]

44. Kuzmicz, K.A.; Pesch, E. Approaches to Empty Container Repositioning Problems in the Context of Eurasian Intermodal Transportation. Omega 2019, 85, 194-213. [CrossRef]

45. Legros, B.; Bouchery, Y.; Fransoo, J. A Time-Based Policy for Empty Container Management by Consignees. Prod. Oper. Manag. 2019, 28, 1503-1527. [CrossRef]

46. Marnasidis, S.; Stamatelatou, K.; Verikouki, E.; Kazantzis, K. Assessment of the Generation of Empty Pesticide Containers in Agricultural Areas. J. Environ. Manag. 2018, 224, 37-48. [CrossRef]

47. Peng, Z.; Wang, H.; Wang, W.; Jiang, Y. Intermodal Transportation of Full and Empty Containers in Harbor-inland Regions Based on Revenue Management. Eur. Transp. Res. Rev. 2019, 11, 7. [CrossRef]

48. Song, Z.; Tang, W.; Zhao, R. Encroachment and Canvassing Strategy in a Sea-cargo Service Chain with Empty Container Repositioning. Eur. J. Oper. Res. 2019, 276, 175-186. [CrossRef]

49. Yu, M.; Fransoo, J.C.; Lee, C.Y. Detention Decisions for Empty Containers in the Hinterland Transportation System. Transp. Res. Part B 2018, 110, 188-208. [CrossRef]

50. Zhao, Y.; Xue, Q.; Zhang, X. Stochastic Empty Container Repositioning Problem with CO2 Emission Considerations for an Intermodal Transportation System. Sustainability 2018, 10, 4211. [CrossRef]

(C) 2019 by the authors. Licensee MDPI, Basel, Switzerland. This article is an open access article distributed under the terms and conditions of the Creative Commons Attribution (CC BY) license (http://creativecommons.org/licenses/by/4.0/). 